\section{A positive effect of intranasal insulin on spatial memory in rats with neonatal diabetes mellitus}

\author{
Oxana V. Chistyakova, \\ Vera M. Bondareva, Valery N. Shipilov, \\ Ivan B. Sukhov, Alexander O. Shpakov \\ Sechenov Institute of Evolutionary \\ Physiology and Biochemistry, Russian \\ Academy of Sciences, St. Petersburg, \\ Russia
}

\section{Abstract}

Type 2 diabetes mellitus (T2DM) is associated with cognitive impairments. However, their causal factors and the approaches to be used in their treatment have not been fully clarified and further study is needed. The aim of this work was to study the effect of intranasal insulin (I-I) on cognitive functions in rats with experimental T2DM. Neonatal rats (5 days old) were treated with an intraperitoneal (i.p.) administration of a single dose of streptozotocin (STZ) $(80 \mathrm{mg} / \mathrm{kg}$ i.p.) which in adult animals leads to impairment of glucose tolerance and mild hyperglycemia, typical of T2DM. The insulin receptor binding in the synaptosomal and liver membranes was evaluated with [125]]-insulin, and the insulin receptor substrate 2 (IRS2) expression in the brain was estimated by RTPCR. Daily I-I (0.48 IU/day) or placebo were delivered to diabetic and non-diabetic rats during a week before and the 39 days of cognition experiments. Spatial memory and learning were studied in a Morris water-maze (MWM) test. The MWM test showed that, in the case of diabetic rats, the latent period for finding the platform (escape latency) and the swimming path length were increased, and the number of annulus crossings decreased compared with control $(\mathrm{P}<0.05)$. I-I normalized cognitive functions in diabetic rats but had no effect on those of non-diabetic animals. Specific insulin binding in the liver of diabetic rats was decreased, indicating peripheral insulin resistance, but changed very little in the brain. In the hypothalamus of diabetic rats, but not in the cortex and the olfactory bulbs, the expression of IRS2 was reduced by $68 \%$ compared with control and was restored after I-I delivery. Rats with neonatal T2DM had cognitive deficit likely associated with impaired IRS2-mediated signaling pathways in the diabetic brain and eliminated by I-I treatment.

\section{Introduction}

Diabetes mellitus (DM) is a complex metabolic disease associated with many complications, including retinopathy, nephropathy, peripheral neuropathy, and cardiovascular and reproductive system dysfunction. DM also induces cerebral disorders referred to as diabetic encephalopathy. They are presented as impaired activity of all cognitive functions, increase in mental subtraction errors, decreased speed of information processing, decreased attention, impaired verbal, visual and working memory, and others. ${ }^{1}$ Patients with insulin-dependent DM, known as type 1 DM (T1DM), and with non-insulin dependent DM, or type 2 DM (T2DM), which differ significantly in etiology and pathogenesis, have a wide range of CNS disorders and complications in common. The recurrent hypoglycemia due to intensive insulin therapy and inappropriate glycemic control in T1DM, and the prolonged hyperglycemia in T2DM are both implicated in cognitive deficit. However, the causal factors inducing CNS complications in DM and the mechanisms of pathogenesis that lead to neurodegenerative diseases have not been fully clarified because of the problems that arise in carrying out a comparative analysis of cognitive functions in healthy individuals and diabetic patients. Diabetic patients differ according to a wide range of parameters, such as age, the quality of metabolic control, the occurrence of associated diseases and noncerebral DM complications, and the severity of hypo- and hyperglycemia. ${ }^{1-4}$ Another problem is a lack of adequate models of experimental DM which can be used to study the influence of the disease on the CNS. Even streptozotocin (STZ) $\mathrm{DM}$, the most typical model of T1DM, with a complete insulin deficiency and prolonged hyperglycemia differs in many respects from human T1DM which is associated with the hypoglycemia episodes provoked by intensive insulin therapy and physical exercise. Several recent studies have been devoted to the cognitive deficit in experimental T1DM, but very few to the relationship between glucose homeostasis and cognitive functions in animal models of T2DM, such as Goto-Kakizaki (GK) and Zucker Diabetic Fatty (ZDF) rats, and rats with a T2DM-like state induced by a high fat diet (HFD) and STZ treatment, similar in some characteristics to human T2DM.-5-8

The data obtained support the fact that, in the brain, the alterations and abnormalities in the hormonal signaling systems regulated by insulin, insulin-like growth factor-1 (IGF-1), leptin, biogenic amines, glutamate and peptide hormones, and the changes in expression of hormones and signal proteins, the components of these systems, disturb growth, differentiation, metabolism and apoptosis in neuronal
Correspondence: Oxana V. Chistyakova, Sechenov Institute of Evolutionary Physiology and Biochemistry, Russian Academy of Sciences, Thorez av. 44, 194223 St. Petersburg, Russia. Tel. + 7.812.552.3117 - Fax + 7.812.552.3012. E-mail: chiosana@yandex.ru

Key words: cognition, diabetes mellitus, insulin receptor substrate, intranasal insulin, rat neonatal model.

Acknowledgments: this work was supported by the Program of the Russian Academy of Sciences Fundamental Sciences to Medicine (2009-2011) and grant n. 09-04-00746 from the Russian Foundation of Basic Research. We express our thanks to Inga Menina for linguistic assistance.

Received for publication: 27 September 2011.

Revision received: 1 November 2011.

Accepted for publication: 2 November 2011.

This work is licensed under a Creative Commons Attribution NonCommercial 3.0 License (CC BYNC 3.0)

(C) Copyright O.V. Chistyakova et al., 2011

Licensee PAGEPress, Italy

Endocrinology Studies 2011; 1:e16

doi:10.4081/es.2011.e16

cells. They also contribute to triggering neurodegenerative processes, and the development of cognitive deficit and other CNS disorders in patients with T2DM and animals with an experimental model of T2DM. ${ }^{9-11}$ In the diabetic brain, insulin, the principal player responsible for pathogenesis of T2DM, and numerous signaling cascades regulated by insulin and involving many regulatory and effector proteins, such as insulin receptor substrate proteins, ${ }^{12}$ phosphatidylinositol 3-kinase (PI 3-kinase), AKT kinase, protein phosphotyrosine phosphatases, ${ }^{13}$ and ERK1/ERK2 kinases, are changed significantly. Dysfunctions in the insulin-regulated signaling system in the brain result in the death of neurons, and neurofibrillary and amyloid-related neurodegenerative diseases (senile dementia, Alzheimer's and Parkinson's diseases, etc.) that are most often associated with T2DM.14,15 Therefore, the treatment of diabetic patients with insulin and the restoration of functional activity of insulinregulated signaling pathways are a reliable approach in the therapy of central and neuroendocrine dysfunctions in DM.

Peripherally administrated insulin and its analogs with prolonged action are widely applied in the treatment of DM. ${ }^{16}$ About $27 \%$ of diabetic patients continue to take insulin for the management of their hyperglycemia. ${ }^{17}$ However, the intensive therapy with peripherally administrated insulin leads to repetitive episodes of moderate to severe hypoglycemia which triggers neurodegenerative processes 
in the brain and contributes to cognitive deficit.1,18 The intranasal administration of insulin has no appreciable influence on the level of peripheral glucose and, therefore, does not provoke hypoglycemic episodes. ${ }^{19,20}$ Intranasal insulin (I-I) is transported directly into the brain and binds with brain insulin receptors (IRs) enriched with hypothalamic neurons responsible for the synthesis and secretion of neuropeptides and neurotransmitters. It has been shown that I-I treatment influences CNS functioning, improves learning and memory, and prevents cognitive decline, cerebral atrophy, and focal cerebral ischemia; it also reduces food intake and body weight. ${ }^{21,22}$ Many studies have examined the influence of I-I on physiological and biochemical processes in the brain and peripheral tissues of healthy humans and non-diabetics, as well as non-diabetic experimental animals. ${ }^{20,21,23-26}$ Despite this, data concerning the influence of central insulin on human and experimental DM are scarce. ${ }^{27,28}$ One of the more recent studies showed that I-I positively influences cognitive dysfunctions in STZinduced T1DM of mouse. ${ }^{29}$

The present study examines the influence of metabolic alterations associated with experimental T2DM on formation of the long-term spatial memory and learning in a Morris watermaze (MWM) test in female rats with a neonatal model of T2DM. The study also aimed to find out whether, and if so how I-I delivery improves cognitive functions in diabetic rats. The influence of I-I on the insulin signaling system in the brain of diabetic rats was assessed by studying the binding parameters of IR and the gene expression insulin receptor substrate-2 protein (IRS2) that is coupled with IR and the intracellular effector proteins, such as PI 3-kinase, phosphotyrosine phosphatase and the components of MAPK cascade. We were interested in the expression of IRS2, because, unlike other IRS proteins, it is present in high concentrations in the hypothalamus and other brain areas and has an important role in many of the hypothalamic effects of insulin on the CNS and peripheral tissues. ${ }^{30,31}$ It has been shown that, in T2DM, there are considerable variations in the expression of genes encoding IR and IRS2 and their functional activity, which is likely to contribute to the development of neurodegenerative processes in the diabetic brain and induce cognitive deficit.

\section{Materials and Methods}

\section{Animals}

The 6-month female rats (Wistar) were housed in plastic sawdust-covered cages with a normal light-dark cycle and free access to food and water. The experiments were carried out under institutional guidelines (the Bioethics Committee, December 23, 2010) and Guidelines for the treatment of animals in behavior research and teaching. ${ }^{32}$ All efforts were made to minimize animal suffering and reduce the number of animals used.

Four groups of animals were investigated: Group C ( $\mathrm{n}=8)$ and Group C-I $(\mathrm{n}=7)$ including control animals without and with I-I administration, Group D $(n=8)$ and Group D-I $(n=7)$ including rats with neonatal T2DM without and with I-I administration, respectively. Before and during the behavioral tests each group was housed in a separate cage.

\section{Neonatal model of type 2 diabetes}

Insulin-independent T2DM was induced by intraperitoneal (i.p.) administration of a single dose of STZ ( $80 \mathrm{mg} / \mathrm{kg}$ ) freshly dissolved in citrate-acidified $0.9 \% \mathrm{NaCl}, \mathrm{pH} 4.5$ to newborn (5-day old) rats. Pups belonging to the control group were injected by saline. Typically, STZ treatment leads to destruction of B cells and, as a result, insulin production is almost completely blocked. However, at the early stages of development of rats, the first week after birth, a partial restoration of insulin-producing function of B cells can occur due to their regeneration. ${ }^{33}$ As a rule, $50-70 \%$ of infant rats treated with STZ show signs of T2DM on reaching the age of 2.5-3 months. ${ }^{34}$ In our experiments, $70 \%$ of 3-month old STZ-treated rats had glucose tolerance, as assessed in the glucose tolerance test (GTT) using i.p. glucose loading ( $2 \mathrm{~g} / \mathrm{kg}$ of body weight).

\section{Intranasal insulin delivery}

I-I delivery to the rat brain was performed as described previously by Thorne and Frey. 35 Crystalline porcine insulin (Sigma, USA) at a concentration of $24 \mathrm{IU} / \mathrm{mL}$ was dissolved in $0.9 \%$ saline, $\mathrm{pH} 4.5$, and administered intranasally to both diabetic and non-diabetic rats daily during a week before and the 39 days of behavioral testing. Each rat was placed in a supine position and an average of $20 \mu \mathrm{L}$ of insulin solution (0.48 IU) was administered with an Eppendorf pipette over alternative nares five $4 \mu \mathrm{L}$ drops every minute. Control animals were given an equal volume of saline.

\section{Morris water maze test}

Throughout the behavioral experiments, the groups of diabetic and non-diabetic rats with and without I-I were investigated. For a week before the experiments, the animals were accustomed to being handled. Spatial training of the rats was performed in an MWM test. ${ }^{36-38}$ Test efficiency was estimated by how long it took the animals to swim in a circular pool (120 $\mathrm{cm}$ in diameter, $30 \mathrm{~cm}$ in depth, filled with turbid water with chalk at $24 \pm 1^{\circ} \mathrm{C}$ ) to find a hidden platform measuring $13 \mathrm{~cm}$ in diameter located $2 \mathrm{~cm}$ below the water level (escape latency).

In the first series of experiments, the animals swam daily for five days. Each rat had four attempts of $120 \mathrm{~s}$. each to search for the hidden platform from four different starting points. The animals were allowed to swim until either they located the platform and climbed on it or when $120 \mathrm{~s}$. had elapsed. If the rats did not find the platform, they were physically placed on it. Between attempts, the animals remained on the platform for a 30-s. rest. Post-testing, rats were warmed under a heat lamp. The day to day decrease in escape latency and the change in the length of the swimming path were taken as indicators of successful spatial learning.

Testing was repeated a month later (second series of experiments) and the rats underwent the same experiments as the first series. In addition, on Day 5 of the first and second series, $40 \mathrm{~min}$. after the basic testing, the rats were placed in the pool for $60 \mathrm{~s}$ after the platform had been removed, and the number of crossings over the previous platform location (annuluses) was recorded. ${ }^{39}$ This parameter provides replicates of the experiment to estimate the strength and accuracy of the memory of the previous platform location. ${ }^{40}$ The swimming path and the escape latency of each rat were recorded by video camera. The data obtained were processed using Real Timer software 1.2 (Open Science Ltd., Russia) and Smart Junior (Panlab, S.L.U., Harvard Apparatus, USA).

\section{Plasma membrane preparation}

After behavioral experiments, the rats were decapitated under anesthetic (mixed ketamine $90 \mathrm{mg} / \mathrm{kg}$ of body weight and xylazine $10 \mathrm{mg} / \mathrm{kg}$ of body weight), and the liver and brain tissues (cerebral cortex, hypothalamus, olfactory bulbs) were dissected and frozen at $-70^{\circ} \mathrm{C}$.

Synaptosomal membranes from the rat brain were prepared according to Havrankova and colleagues.41 The brain tissues without cerebellum were dissected on ice and homogenized in ice-cold $1 \mathrm{mM} \mathrm{NaHCO}$ buffer, $\mathrm{pH} 7.5$ (Buffer A) containing a cocktail of protease inhibitors ( $2 \mu \mathrm{M}$ leupeptin, $0.1 \%$ bacitracin and $2 \mathrm{mM}$ phenylmethylsulphonyl fluoride). The crude homogenate was centrifuged at $1000 \times$ g for $20 \mathrm{~min}$. at $4^{\circ} \mathrm{C}$. The resulting pellet was discarded and the supernatant was centrifuged at $30,000 \times \mathrm{g}$ for $30 \mathrm{~min}$. The pellet was resuspended in Buffer $\mathrm{A}$ and used in the binding experiments.

Plasma membranes from the rat liver were prepared as described by Neville. ${ }^{42}$ Pieces of the liver were homogenized in Buffer A, filtered and centrifuged at $1000 \times \mathrm{g}$ for $20 \mathrm{~min}$. at $4^{\circ} \mathrm{C}$. The pellets were resuspended in the same 
buffer and $70 \%$ sucrose solution was added to take the solution density to 1.408 . The material obtained was centrifuged in a 1.420/1.408/1.405 gradient of sucrose at $100,000 \times \mathrm{g}$ for $90 \mathrm{~min}$. at $4^{\circ} \mathrm{C}$. The flotation layer was collected, washed with Buffer A and centrifuged at 80,000 $\times$ g for $30 \mathrm{~min}$. at $4^{\circ} \mathrm{C}$. The resulting pellet was resuspended in the same buffer to produce the membrane fraction with a protein concentration in the range of $1-3 \mathrm{mg} / \mathrm{mL}$ and stored at $-70^{\circ} \mathrm{C}$. The protein concentration of each membrane preparation here and in later experiments was measured according to the method of Bradford using $\gamma$-globulin as a standard.

\section{Insulin binding to rat synaptosomal and liver membranes}

The insulin receptor binding in the synaptosomal and liver membranes was estimated by competition displacement of labeled [125I]insulin with the unlabeled hormone, as previously described. ${ }^{43,44}$ The insulin-binding assay in the liver membranes was carried out in Phosphate-buffered saline, pH 7.5, containing a cocktail of protease inhibitors (Buffer B). The binding in the synaptosomal membranes was carried out in $100 \mathrm{mM}$ HEPES buffer, $\mathrm{pH}$ 7.5 , containing $120 \mathrm{mM} \mathrm{NaCl}, 1.2 \mathrm{mM} \mathrm{MgSO}_{4}$, $2.5 \mathrm{mM} \mathrm{KCl}, 15 \mathrm{mM}$ sodium acetate, $10 \mathrm{mM}$ glucose, 1 mM EDTA with a cocktail of protease inhibitors (Buffer C). A fraction of liver or brain membranes ( $0.5 \mathrm{mg}$ of protein) was incubated overnight at $4^{\circ} \mathrm{C}$ in a corresponding buffer containing unlabeled porcine insulin at a concentration of $0.01-1000 \mathrm{ng} / \mathrm{mL}$ and radioactive [ ${ }^{255}$ I]-insulin (20,000 counts/min). Non-specific binding was controlled by incubating the material in the presence of 10 $\mu \mathrm{g} / \mathrm{mL}$ of unlabeled insulin. To terminate the reaction, the probes were washed by $1 \mathrm{~mL}$ of Buffer B (the liver membranes) or C (the synaptosomal membranes) and centrifuged at $2000 \times \mathrm{g}$ for $10 \mathrm{~min}$. The centrifuge procedure was repeated and the radioactivity of the precipitate was measured by an NZ32 $\gamma$-counter (Hungary). Binding data were analyzed using Scatchard plots, taking into account the highaffinity low-capacity receptors (at a concentration of unlabeled insulin below $60 \mathrm{ng} / \mathrm{mL}$ ) and low-affinity high-capacity receptors (at a concentration of unlabeled insulin over 60 $\mathrm{ng} / \mathrm{mL})$.

\section{The expression of IRS2 gene in the brain}

Total RNA from the cerebral cortex, hypothalamus and olfactory bulbs was isolated using TRI-reagent (Sigma, USA) according to the manufacturer's instructions. All RNA samples were treated with DNAase I (Fermentas, USA) to remove the contaminating genomic DNA. Absorbance measurements at $260 \mathrm{~nm}$ in water were used to adjust the stock concentra- tion of all RNA samples to $1 \mu \mathrm{g} / \mathrm{mL}$, assuming the absorbance of 1 to be equivalent to RNA at $40 \mu \mathrm{g} / \mathrm{mL}$. The following quality control standards were applied: purity of RNA samples $\left(\mathrm{A}_{260} / \mathrm{A}_{280}\right)$ was more than 1.8 , the $18 \mathrm{~S}$ and the $28 \mathrm{~S}$ ribosomal RNA bands were present when the samples were analyzed using agarose gel electrophoresis. The RNA samples were subjected to a reverse transcription reaction to synthesize single strand cDNAs using the first strand cDNA synthesis kit (Fermentas, USA). Amplification of the 234-base pair cDNA fragment encoding IRS2 was performed on an MJ Mini Thermal Cycler (Bio-Rad, USA). Thermo cycling conditions were $95^{\circ} \mathrm{C}$ for $3 \mathrm{~min}$, followed by 34 cycles of $95^{\circ} \mathrm{C}$ for $20 \mathrm{~s}, 52^{\circ} \mathrm{C}$ for 30 $\mathrm{s}$, and $72^{\circ} \mathrm{C}$ for $30 \mathrm{~s}$, and the final elongation at $72^{\circ} \mathrm{C}$ for $3 \mathrm{~min}$. The following primers were used: 5'-GAGGACTGAGGAAGAGGAC-3' (forward) and 5'-GGTTACTGCTGGAACTCTTG-3' (reverse). To control experimental variations in sample processing, primers 5'-CAAGGTCATCCATGACAACTTTG-3'(forward) and 5'GTCCACCACCCTGTTGCTGTAG-3' (reverse) synthesizing the 496-base pair cDNA fragment encoding rat glyceraldehyde 3-phosphate dehydrogenase (GAPDH) were used in the PCR amplification. The incubation mixture included (final concentration): $1 \times$ Taq Buffer including $\left(\mathrm{NH}_{4}\right)_{2} \mathrm{SO}_{4}, 0.2 \mathrm{mM}$ of each dNTP, 2 $\mathrm{mM} \mathrm{MgCl}_{2}, 0.05 \mathrm{U} / \mu \mathrm{L}$ Taq DNA-polymerase (Fermentas, USA), $1 \mu \mathrm{L}$ of cDNA sample, 1.75 $\mu \mathrm{M}$ of each IRS2 primer and $0.3 \mu \mathrm{M}$ of each GAPDH primer. The total volume of reaction mixture was $20 \mu \mathrm{L}$. Each reaction was performed in triplicate. The values of band fluorescence intensity were obtained using Total Lab TL120 1D v2009 software (Nonlinear Dynamics, UK). The intensity of IRS2 bands was normalized to GAPDH intensity and expressed as arbitrary units.

\section{Glucose, insulin, HbA1c, triglyceride, cholesterol and HDLs assays}

Whole blood was obtained from the tail vein under local (sc) anesthesia with $2 \%$ lidocaine per $2-4 \mathrm{mg} / \mathrm{kg}$ of body weight. Blood glucose was measured using One Touch Ultra (USA) test strips and a glucometer (Life Scan
Johnson \& Johnson, Denmark). The insulin concentration in rat serum was determined using Rat Insulin ELISA (Mercodia AB, Sweden). Triglycerides and total cholesterol were determined by Trinder-based (GPO-PAP and CHOD-PAP, respectively) colorimetric endpoint method, high density lipoprotein (HDL)cholesterol by direct clearance method, and HbAlc concentration by immunoassay method using kits from Randox Laboratories Ltd., (UK) and Sapphire 400 automated clinical chemistry analyzer (Niigata Mechatronics Co., Ltd., Japan).

\section{Statistical analysis}

Data are presented as the mean \pm SEM. Data analysis was carried out using one-way analysis of variance (ANOVA) followed by Student's Newman-Keuls post hoc test or unpaired t-test as required. For determination of the insulin receptor binding and IRS2 expression, the values are the mean \pm SEM of three individual experiments, each performed in triplicate. The difference was considered significant at $\mathrm{P}<0.05$.

\section{Results}

\section{Characteristics of neonatal diabetes}

The experimental animals were tested for weight, plasma glucose and insulin levels, GTT, glycated hemoglobin $\mathrm{HbA}_{1 \mathrm{c}}$ level, and lipid metabolism markers, as well as for binding characteristic of insulin receptors (IRs) in the brain and in the periphery tissues (the liver). Body weight of the 180-day old diabetic rats (Group D) increased less than that of their respective control (Group C) (Table 1). The diabetic animals had long-term moderate hyperglycemia (fasting blood glucose level was no higher than $7 \mathrm{mM}$ ) and slightly decreased plasma insulin level, which agrees well with the corresponding parameters of the rats with a neonatal model of T2DM obtained by others. ${ }^{33,34}$ In GTT, 120 min. after glucose load, the concentration of glucose in the blood of control rats (Group $\mathrm{C}$ ) reached normal levels. In contrast, in diabetic rats (Group D) it did not decrease and remained much higher compared to controls, indicating insulin resistance typical of T2DM (Table 2). Triglycerides and

Table 1. Body weight, fasting plasma glucose and insulin levels in non-diabetic and diabetic rats with and without intranasal insulin treatment in the beginning and at the end (Day 39) of physiological experiments.

\begin{tabular}{|c|c|c|c|c|c|c|}
\hline \multirow[t]{2}{*}{ Rats } & \multicolumn{2}{|c|}{ Body weight, g } & \multicolumn{2}{|c|}{ Plasma glucose, mM } & \multicolumn{2}{|c|}{ Plasma insulin, ng/mL } \\
\hline & $\begin{array}{l}\text { Prior to I-I } \\
\text { treatment }\end{array}$ & Day 39 & $\begin{array}{l}\text { Prior to I-I } \\
\text { treatment }\end{array}$ & Day 39 & $\begin{array}{l}\text { Prior to I-I } \\
\text { treatment }\end{array}$ & Day 39 \\
\hline Group C ( $\mathrm{n}=8)$ & $218 \pm 14$ & $257 \pm 14$ & $5.2 \pm 0.3$ & $4.9 \pm 0.4$ & $2.3 \pm 0.3$ & $2.1 \pm 0.4$ \\
\hline Group C-I $(\mathrm{n}=7)$ & $225 \pm 15$ & $253 \pm 16$ & $5.5 \pm 0.6$ & $4.8 \pm 0.8$ & $2.1 \pm 0.4$ & $2.2 \pm 0.4$ \\
\hline Group D (n=8) & $243 \pm 16$ & $277 \pm 15$ & $6.7 \pm 1.0$ & $6.0 \pm 0.8$ & $1.4 \pm 0.4$ & $1.5 \pm 0.6$ \\
\hline Group D-I ( $\mathrm{n}=7)$ & $232 \pm 12$ & $264 \pm 17$ & $6.6 \pm 1.1$ & $6.1 \pm 0.5$ & $1.9 \pm 0.5$ & $2.1 \pm 0.5$ \\
\hline
\end{tabular}


HDL-cholesterol levels, such as concentration of glycated hemoglobin $\mathrm{HbA}_{1 c}$ were increased in the diabetic rats. This is characteristic of T2DM (Table 3).

Insulin receptor binding in the brain and liver of diabetic compared with non-diabetic rats

There was practically no difference in the insulin binding capacity of IRs in the synaptosomal membranes isolated from the brain (the cerebral cortices, hippocampus, and striatum) of rats with neonatal T2DM compared with controls (Table 4). At the same time, the insulin binding capacity of receptors in the liver membranes in T2DM was lower compared with healthy animals due to a smaller number of IRs with high and low affinity. The affinity of IRs in the brain of diabetic rats remained practically unchanged (Table 4). Specific insulin binding in the liver of diabetic rats was decreased, which indicates insulin resistance of this peripheral tissue to insulin, typical of noninsulin dependent DM. There were no significant changes in the binding characteristics of brain IRs.

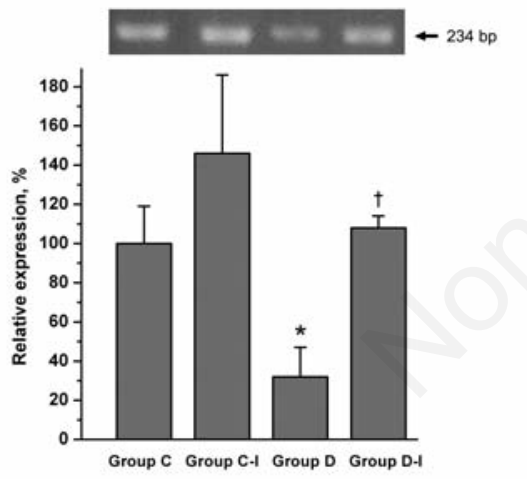

Figure 1. RT-PCR of IRS2 mRNA in the hypothalamus of non-diabetic and diabetic rats with and without intranasal insulin treatment. PCR products (upper slide) were separated on a $1.5 \%$ agarose gel with an appropriate DNA ladder and visualized with ethidium bromide. A 234 base pairs (bp) product containing IRS2 mRNA sequences was observed, as confirmed by DNA sequencing. The fluorescence intensity of IRS2 bands was normalized to GAPDH intensity and expressed as arbitrary units. The level of IRS $2 \mathrm{mRNA}$ in the control group was taken as $100 \%$. *: statistically significant difference between Group D and Group $C$ at $P<0.05$. †: statistically significant difference between Group D-I and Group D at $\mathrm{P}<0.05$.
IRS2 expression in the brain of diabetic compared with

non-diabetic rats

Using RT-PCR, we showed that there was practically no difference in the expression of the IRS2 gene in the cerebral cortex and the olfactory bulbs of diabetic rats compared to controls (data not shown). At the same time, the expression of the IRS2 gene in the hypothalamus of diabetic animals decreased by $68 \%$ compared with controls (Figure 1). The decrease in IRS2 mRNA level in the hypothalamus is likely to be associated with impairment of the insulin signal transduction in this brain area in neonatal DM.

\section{The influence of intranasal insulin} on body weight and biochemical

\section{parameters in diabetic rats}

In our study, I-I treatment had a slight influence on the body weight and plasma glucose level in all groups of animals. The decreased level of plasma insulin in the diabetic rats was restored (Table 1). Using GTT, we found that 120 min. after glucose load the plasma glucose level in insulin-treated diabetic rats (D-I) did not decrease to normal values and was higher in comparison with their respective control. At the same time, diabetic animals from Group DI had a lower glucose level after load (D) compared to untreated animals due to partial restoration of insulin resistance in rats receiving I-I (Table 2). I-I treatment led to a decrease in enhanced concentration of triglycerides, but had little effect on the other biochemical parameters under study (Table 3 ).

\section{The influence of intranasal insulin on IRS2 expression in the brain of diabetic and non-diabetic rats}

Intranasal insulin induced an increase in IRS2 gene expression in the hypothalamus of non-diabetic rats and fully restored IRS2 expression, which in the hypothalamus of diabetic rats was decreased (Figure 1). It had no effect on the levels of IRS2 mRNA in the cortex and olfactory bulbs which, as has been mentioned above, in T2DM did not differ significantly from normal values (data not shown). The data obtained give evidence for intranasal insulin-induced restoration of functional activity of the initial components of insulin signal-

Table 2. Fasting blood glucose (FBG) and glucose tolerance test (GTT) in non-diabetic and diabetic rats with and without intranasal insulin treatment one day before the experiments.

\begin{tabular}{lcccc} 
Rats & FBG & $\begin{array}{c}\text { Plasma glucose, mM } \\
\text { GIT } \\
(30 \text { min. })\end{array}$ & $\begin{array}{c}\text { GIT } \\
(60 \text { min. })\end{array}$ & $\begin{array}{c}\text { GIT } \\
(120 \text { min. })\end{array}$ \\
Group C $(\mathrm{n}=8)$ & $5.0 \pm 0.4$ & $11.8 \pm 1.2$ & $7.0 \pm 1.0$ & $5.6 \pm 0.7$ \\
Group C-I $(\mathrm{n}=7)$ & $5.1 \pm 0.7$ & $10.2 \pm 1.4$ & $7.4 \pm 1.3$ & $5.1 \pm 0.9$ \\
\hline Group D $(\mathrm{n}=8)$ & $6.5 \pm 1.1$ & $21.4 \pm 2.9$ & $17.1 \pm 4.2$ & $13.5 \pm 2.1$ \\
Group D-I $(\mathrm{n}=7)$ & $6.4 \pm 0.9$ & $17.9 \pm 3.2$ & $13.5 \pm 1.9$ & $10.7 \pm 1.2$ \\
\hline
\end{tabular}

Table 3. Levels of $\mathrm{HbA}_{1}$, triglycerides, total cholesterol and HDL-cholesterol in the blood of non-diabetic and diabetic rats with and without intranasal insulin treatment.

\begin{tabular}{lllll} 
Rats & HbA $_{\text {Ics }} \%$ & $\begin{array}{c}\text { Triglycerides, Total cholesterol, } \\
\mathbf{m M}\end{array}$ & $\begin{array}{c}\text { HDL- } \\
\text { mM }\end{array}$ & $\begin{array}{c}\text { cholesterol, } \\
\text { mM }\end{array}$ \\
Group C $(\mathrm{n}=8)$ & $6.62 \pm 0.26$ & $0.84 \pm 0.32$ & $1.95 \pm 0.25$ & $0.49 \pm 0.13$ \\
Group C-I $(\mathrm{n}=7)$ & $6.49 \pm 0.44$ & $0.93 \pm 0.55$ & $1.81 \pm 0.45$ & $0.46 \pm 0.10$ \\
\hline Group D $(\mathrm{n}=8)$ & $8.50 \pm 1.06^{*}$ & $1.47 \pm 0.15^{*}$ & $1.86 \pm 0.14$ & $0.54 \pm 0.10$ \\
Group D-I $(\mathrm{n}=7)$ & $8.12 \pm 0.76^{*}$ & $1.19 \pm 0.23$ & $1.88 \pm 0.24$ & $0.64 \pm 0.12$ \\
\hline
\end{tabular}

* statistically significant difference between Group DM and Group C or Group DM-I and Group C-I at P $<0.05$

Table 4. Binding characteristics of insulin receptors (IRs) in the synaptosomal and the liver plasma membranes of control and diabetic rats.

\begin{tabular}{|c|c|c|c|c|c|}
\hline Rats & $\begin{array}{l}\text { Bsp } \\
\mathrm{K}_{\mathrm{d}}\end{array}$ & $\begin{array}{l}\text { High affinity } \\
\mathrm{R}_{0}\end{array}$ & $\begin{array}{c}\text { receptors } \\
\mathrm{K}_{\mathrm{d}}\end{array}$ & $\begin{array}{l}\text { Low affinity } \\
\mathbf{R}_{0}\end{array}$ & receptors \\
\hline \multicolumn{6}{|l|}{ Brain } \\
\hline Control rats $(\mathrm{n}=8)$ & $5.6 \pm 0.7$ & $1.63 \pm 0.27$ & $93 \pm 20$ & $37.9 \pm 3.5$ & $1000 \pm 175$ \\
\hline Diabetic rats $(n=8)$ & $6.2 \pm 1.0$ & $1.49 \pm 0.21$ & $82 \pm 16$ & $43.2 \pm 8.8$ & $1120 \pm 190$ \\
\hline \multicolumn{6}{|l|}{ Liver } \\
\hline Control rats $(\mathrm{n}=8)$ & $15.3 \pm 1.9$ & $2.15 \pm 0.37$ & $305 \pm 25$ & $55.9 \pm 9.6$ & $4470 \pm 325$ \\
\hline Diabetic rats $(n=8)$ & $11.2 \pm 1.0^{*}$ & $2.02 \pm 0.38$ & $233 \pm 32 *$ & $57.3 \pm 7.3$ & $3425 \pm 410^{*}$ \\
\hline
\end{tabular}

Bsp: percentage of specific binding per $0.5 \mathrm{mg}$ of membrane protein; $\mathrm{K}_{d}$, affinity of the IRs expressed as a constant of dissociation $(\mathrm{nM}) ; \mathrm{R}_{0}$ the number of receptors (fmo//0.5 mg of membrane protein). ${ }^{*}$ statistically significant difference between diabetic and control rats at $\mathrm{P}<0.05$. 
ing system in the hypothalamus in DM and suggest IRS2 as a target of therapeutic action of intranasally delivered hormone.

\section{The study of cognitive function of non-diabetic rats in the MWM test}

0n Days 1 and 5 (the first series) and on Days 35 and 39 (the second series) of the experiment, there was no essential difference in the swimming path length between control (Group C) and insulin-treated non-diabetic rats (Group C-I) (Figure 2A and B). The learning processes estimated according to the duration and dynamics of the latent period for finding the platform appeared to be similar in Group C and Group C-I, except that on Day 1 of the first series the insulin-treated rats learned the task quicker (Figure 3). In both groups of non-diabetic animals, the escape latency reached the plateau on Day 4 of the first series, and the information about location of the hidden platform was maintained throughout the experiments (the second series) (Figure 3 ). In the first series and on Day 1 of the second series the I-I-treated non-diabetic rats on average located the hidden platform much quicker compared with control animals (Table 5). But on the last day of the second series there was no difference between Groups C and C-I. On Days 5 and 39 of testing there was no difference in the number of annulus crossings by the control (Group C) and the insulin-treated rats (Group C-I) (Table 6). These data suggest that while the effect of I-I on long-term spatial memory in healthy animals with no cognitive deficit is rather weak, it has a significant influence on memory formation, especially in the initial period of the MWM test.

\section{Diabetic rats show significant impairment in an MWM task}

The real-time swimming tracking showed a significant difference between swimming path length in the case of diabetic and control rats, especially at the beginning of the second series (Figure 2A and C). In the first series of experiments, it took the diabetic rats (Group D) on average twice as long as control animals to locate the platform (Figure 3). The dynamics of time reduction in locating the platform (learning) was less pronounced compared with control animals. In the second series of experiments, the escape latency in the case of diabetic rats was 3-5 times longer than that of

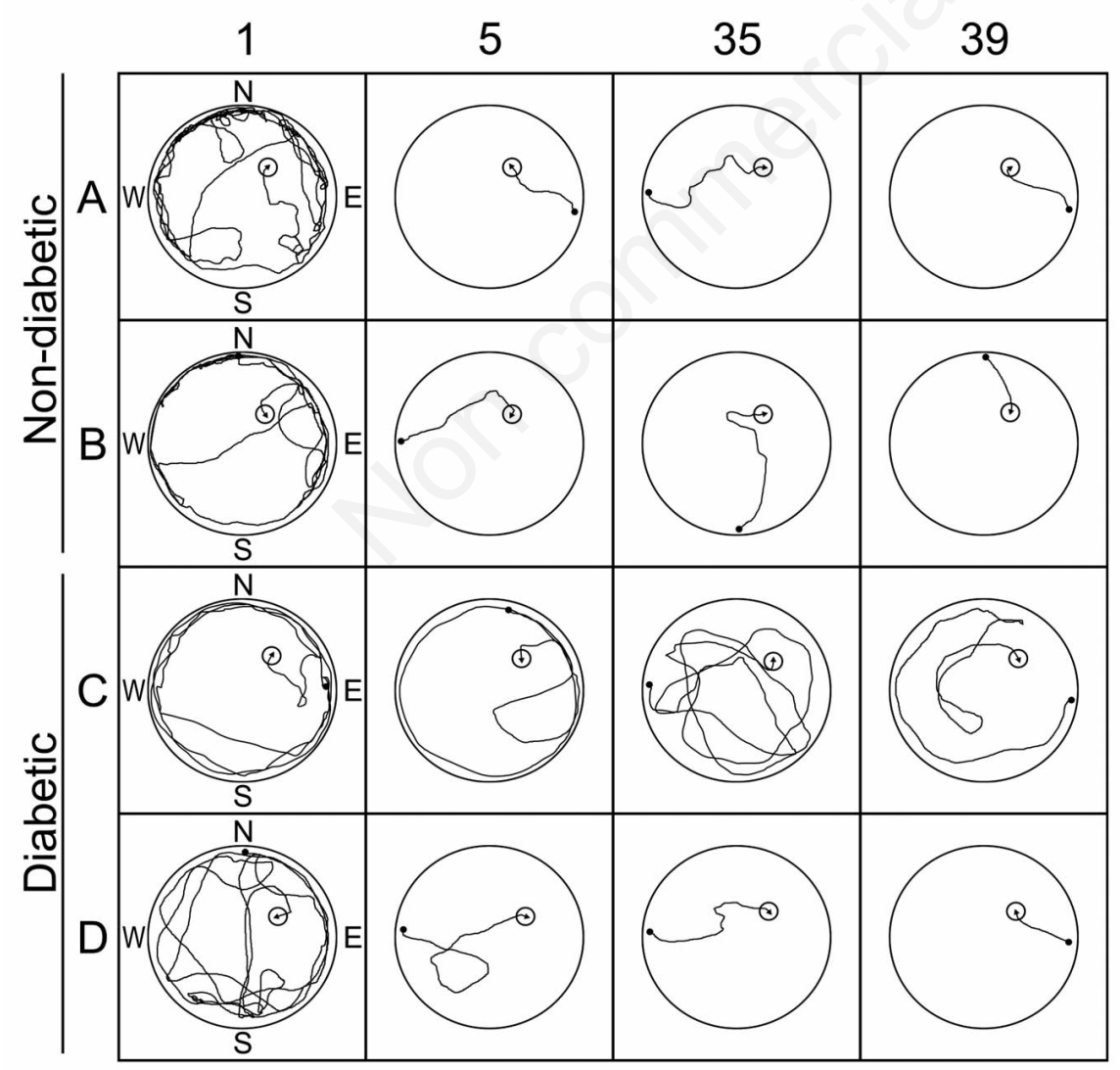

Figure 2. Typical swimming patterns of non-diabetic and diabetic rats with and without intranasal insulin treatment in a Morris water-maze test. A: Group C; B: Group C-I; C: Group D; D: Group D-I. Days 1, 5, 35 and 39 of the experiment. Starting points: N North; S South; W West; E East. control animals. On the first day of the second series, the search time for locating the platform by diabetic rats increased by $70 \%$ compared with the last day of the first series, while there was no change in the control (Group C) and the I-I -treated non-diabetic rats (Group CI). The escape latency for the diabetic rats was 5 times longer than in the respective control. There was no difference in the swimming speed between diabetic rats and control rats except on the last day of experiments when it was $31 \%$ lower than control (Table 5). There was a decrease in the number of annulus crossings in Group D of 45\% in the first series and $40 \%$ in the second series compared with control (Table 6). These findings indicate the development of cognitive deficit in rats with neonatal T2DM, as illustrated by impairment of their learning and spatial memory in comparison with healthy animals.

\section{Intranasal insulin restores the spatial memory and learning \\ of diabetic rats}

Intranasal administration of insulin in the diabetic rats (Group D-I) made the latency period an average of three times shorter (Figure 3). The maximal effect of intranasal insulin was a maximum of five times the reduction in escape latency in the first and second series of experiments. As far as insulin-treated diabetic rats are concerned, in the second series the swimming path lengths were similar to those of control and insulintreated non-diabetic rats, being significantly shorter than in the case of non-treated diabetic animals (Figure 2D). The swimming speed

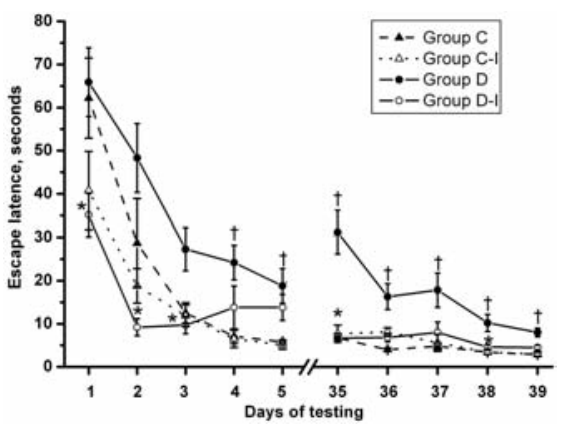

Figure 3. The duration and the dynamics of the latent period for finding the hidden platform by non-diabetic and diabetic rats with and without intranasal insulin treatment in a Morris water maze test. The first series includes Days 1-5; the second series includes Days 35-39. *: statistically significant difference between Group D-I and Group $D$ at $P<0.05$. $\dagger$ : statistically significant difference between Group $D$ and Group $C$ at $P<0.05$. 
of rats in Group D-I was much higher compared with Group D and was closer to that of rats in Group C-I, being similar to both groups of healthy animals at the end of the experiment (Day 39) (Table 5). There was an increase in the number of crossings of the platform's original location by the rats in Group D-I compared with those in Group D, and on Day 39 of testing the difference in the number of annulus crossings between animals in Groups D and D-I was statistically significant at $\mathrm{P}<0.05$ (Table 6). In the first series of experiments, on Day 5 of testing, the diabetic rats in Group D-I had fewer annulus crossings than control animals, while in the second series the number of crossings of these rats, after prolonged intranasal delivery of insulin, was closer to the corresponding values of healthy rats. These results suggest that intranasal insulin improves the long-term spatial memory in rats with T2DM to levels similar to those of healthy animals. A decrease in the time required to locate the hidden platform, a shortening of the swimming path length, as well as an increase in the swimming speed and of the number of annulus crossings in the case of intranasal insulintreated diabetic animals, all show the insulininduced improvement of learning in rats with the neonatal model of DM.

\section{Discussion}

Cognitive deficit with impaired abstract reasoning and complex psychomotor functioning occurs in patients with DM. Alterations of the cognitive functions are likely to occur at the late stages of disease due to the triggering of neurodegenerative processes in the brain of diabetic individuals.,35-50 A high prevalence of DM-induced CNS diseases and their contribution to the physical and psycho-emotional state of patients with diabetes makes the study of etiology and pathogenesis of the disease important. At present, little is known about the molecular mechanisms and biochemical processes responsible for the development of DM-induced CNS complications. The best approach to solving this problem is to investigate new experimental models of DM accompanied by cognitive deficit and find ways of preventing pathological changes in the diabetic human brain.

The data on cognitive dysfunctions of animals with experimental T2DM are controversial because different models and a variety of physiological approaches have been used to assess learning and memory. These include mutant GK and ZDF rats with obesity, insulin resistance and mild hyperglycemia, KKAy mice with hyperinsulinemia, impaired glucose tolerance and increased oxidative stress, and also

Table 5. Swimming speed $(\mathrm{cm} / \mathrm{s}$.) up to the hidden platform in the first and second series of experiments in a Morris water maze test.

\begin{tabular}{lllll}
\hline & \multicolumn{2}{c}{ First series } & \multicolumn{2}{c}{ Second series } \\
& Day 1 & Day 5 & Day 35 & Day 39 \\
Group C $(\mathrm{n}=8)$ & $12.4 \pm 1.9$ & $21.8 \pm 1.3$ & $17.7 \pm 0.8$ & $32.2 \pm 3.5$ \\
Group C-I $(\mathrm{n}=7)$ & $22.3 \pm 4.5^{*}$ & $25.5 \pm 1.9$ & $24.2 \pm 3.5$ & $32.1 \pm 2.1$ \\
\hline Group D $(\mathrm{n}=8)$ & $14.6 \pm 0.8$ & $18.9 \pm 1.0$ & $15.0 \pm 1.3$ & $22.1 \pm 2.3^{+}$ \\
Group D-I $(\mathrm{n}=7)$ & $20.5 \pm 1.2^{*}$ & $22.1 \pm 1.7$ & $20.9 \pm 1.8$ & $33.4 \pm 2.7^{*}$ \\
\hline
\end{tabular}

*statistically significant difference between Group C-I and Group C or Group D-I and Group D at $\mathrm{P}<0.05$. ${ }^{\dagger}$ Statistically significant difference between Group D and Group C at $\mathrm{P}<0.05$.

Table 6. Number of annulus crossings (units) of healthy and diabetic rats with and without intranasal insulin treatment in the first and second series of experiments in a Morris water maze test.

\begin{tabular}{lcc} 
Rats & First series (Day 5) & Second series (Day 35) \\
Group C $(\mathrm{n}=8)$ & $5.8 \pm 0.9$ & $7.0 \pm 0.4$ \\
Group C-I $(\mathrm{n}=7)$ & $5.7 \pm 0.7$ & $6.8 \pm 0.4$ \\
\hline Group D ( $=8)$ & $3.1 \pm 0.8^{+}$ & $4.6^{+} \pm 0.6^{+}$ \\
Group D-I $(\mathrm{n}=7)$ & $4.4 \pm 1.0$ & $7.8^{*} \pm 0.7^{*}$ \\
\hline
\end{tabular}

*statistically significant difference between Group D-I and Group D at $\mathrm{P}<0.05 .{ }^{\dagger}$ Statistically significant difference between Group D and Group $\mathrm{C}$ at $\mathrm{P}<0.05$.

rats with symptoms of T2DM induced by HFD and treated with low doses of STZ. ${ }^{-5,51-53}$ Some authors failed to detect the changes in the cognitive functions of the animals with obesity and T2DM, while on the contrary, others reported considerable impairment of behavior, learning and memory.

The study of ZDF rats with the symptoms of T2DM in an MWM test showed that they had learned how to manage the test, although control animals were swimming much faster than diabetic animals. ${ }^{51}$ The integrity of synaptic function was also preserved in ZDF rats as no alterations in long-term potentiation were observed in the CA1 area of the hippocampus. The authors came to the conclusion that the resistance of ZDF rats to cognitive dysfunctions might be related to the protective action of moderate hyperinsulinemia typical of this model, and also with a short duration of DM. At the same time, some authors reported a significant impairment of memory associated with abnormalities in the hippocampus activity in obese rats.6,52 Female KKAy mice were produced from a cross between yellow obese Ay male mice and glucose-intolerant black KK female mice. Shuttle avoidance and the MWM tests showed significant impairment of cognitive functions. ${ }^{53}$ Stroke-induced brain damage was observed and cognitive deficit deteriorated in rats treated for two months with HFD followed by low-dose STZ injection to induce T2DM. This was illustrated by the impaired performance of rats in the MWM test. It has been suggested that these cognitive dysfunctions are associated with increased $\beta$-amyloid peptide generation and cytotoxicity, and with the activation of caspases, pro-apoptotic spe- cific proteases. ${ }^{8}$

A neonatal model of T2DM was used to study cognitive deficit. This is a good cost-effective alternative compared to genetic models and regular screening experiments, and may be useful to investigate long-term complications of T2DM. This model is considered to be a better tool to clarify the mechanisms associated with the insulin resistance and the regeneration of the B cells, ${ }^{54}$ although it has not previously been used in behavior experiments. Neonatal DM was characterized by insulin resistance, which is seen as a considerable decline in the glucose-induced insulin release with a decrease in the maximal response to hormone, and by a slight but consistent rise in blood glucose levels in fasted and fed basal states. ${ }^{55}$ It was shown that, unlike injection of a single high dose of STZ which produces T1DM in adult rats, STZ injected during the first week after birth leads to the development of T2DM. ${ }^{34}$ STZ injection to infant rats induces destruction of most B cells. However, some of these cells survive. They begin to form new islets from the small pancreatic ducts and start synthesizing insulin again. As a result, restored insulin secretion allows the animals to live long without insulin treatment. It does, however, induce insulin resistance in peripheral tissues, in particular the liver. In our case, at six months of age, the diabetic rats with neonatal DM had a pronounced decrease in binding characteristics of IRs in the liver, which is one of the molecular mechanisms responsible for glucose tolerance. The development of insulin resistance in the peripheral tissues along with moderate hyperglycemia and lipid metabolism alterations which we 
identified are typical of T2DM.

In the present study, we showed that the cognitive functions of rats with neonatal T2DM were impaired. In an MWM test, diabetic animals, compared to control, demonstrated a significant increase in duration of the latent period for finding the hidden platform, a less pronounced dynamic of the decrease in time required to locate the platform in the first series of experiments, an increase in the swimming path length, and a significant decrease in annulus crossings; all are indicative of problems in intellectual development and learning. The longer time allocated to cope with the test and the increase in swimming path length in diabetic rats in the second series demonstrates impairment of spatial memory functioning. These, together with the considerable differences in swimming speed and number of crossings in the diabetic and control animals suggest impairment of a wide spectrum of overall cognitive and memory functions in rats with neonatal DM2. In conclusion, the study of rodents with neonatal DM in a water maze test would help to further clarify the mechanisms and dynamics of T2DMinduced CNS dysfunctions.

The main causes underlying DM-induced CNS complications are deterioration of hormonal signaling systems of the brain and peripheral tissues. ${ }^{56-58}$ Although in DM CNS signaling cascades regulated by IGF-1, leptin and neurohormones change, ${ }^{11}$ we have focused on the alterations in the upstream components of the insulin signaling system, such as IR and IRS2, diffusely expressed in different brain areas. The abnormalities of the functional activity of these proteins contribute greatly to the etiology and pathogenesis of DM-induced CNS disorders. ${ }^{13}$ Unlike in the liver, we found no changes in total binding of IRs and their affinity to the hormone in the brain of rats with neonatal T2DM. These findings are consistent with the data on the lack of changes in IR expression in the frontal cortex of 8-month old rats with spontaneous onset of DM. 59

According to our data, a decrease in the IRS2 expression in the hypothalamus of diabetic rats was $32 \%$ that of the control. This can be attributed to impairment of the insulin signal transduction at the stage of IRS-mediated coupling between hormone-activated IR and the downstream effector proteins. The hypothalamus, being the most insulin-responsive brain area, contributes to whole-body glucose homeostasis, regulation of feeding behavior and pituitary secretion via the IRS-PI 3-kinase signaling pathway. In the hypothalamus, the insulin signaling system is the key element of a complex network integrating a variety of signaling systems regulated by neuromediators and neurotransmitters, in particular dopamine and serotonin, controlling cognitive functions. ${ }^{60}$ Therefore, IRS2-mediated abnormali- ties of insulin signaling in the hypothalamus of diabetic rats are likely to be among the causes of cognitive deficit.

Our suggestion finds confirmation in the results of other authors. They showed that there are considerable changes in the functional activity of IRS2 in the diabetic hypothalamus which is closely associated both with cognitive functions and with central and peripheral glucose metabolism. ${ }^{12,61}$ There is evidence to show that the knockout of gene encoding IRS2 leads to a T2DM-related state and induces neurodegenerative diseases associated with T2DM. The deletion of the gene encoding IRS2 leads to weakening of hypothalamic insulin signaling and increases food intake and hepatic glucose production. ${ }^{2}$ Mice with IRS2 gene knockout have CNS abnormalities and pronounced resistance to insulin, typical of T2DM. ${ }^{63}$ Female mice lacking the IRS2 gene are fertile, hyperphagic and obese. ${ }^{64}$ These data allow us to suggest that IRS2 supports the transduction of a large number of growth-promoting and metabolic signals in the brain. The involvement of IRS2 in the brain insulin action is confirmed by the fact that intracerebral insulin induces rapid phosphorylation of IRS2 and activation of downstream signal proteins, in particular PI 3-kinase. ${ }^{65}$ It should be noted that IRS1, another protein of the 6-member IRS family playing a key role in the functioning of peripheral tissue, is widely distributed in the brain. It is not concentrated in the hypothalamus and other brain areas enriched with IRs. ${ }^{6} 6$ Transgenic mice lacking neuronal IRS1 have no large-scale disorders of the regulatory effects of insulin. ${ }^{67}$

Changes in IRS2 expression in the brain of diabetic rats were area-specific and did not involve either the cortex or the olfactory bulbs. This proves that alterations of functional activity and expression of signal proteins, components of insulin and other hormonal systems, can be traced in some brain areas but fail to be revealed in the others. ${ }^{9,63,68,69}$ Such area-specific changes may be an important factor causing the disturbances in the functioning of the brain hormonal network in DM, which leads to CNS complications and dysfunctions in the peripheral organs and tissues.

Now insulin and its analogs with prolonged action are used to treat and to prevent DMinduced complications, including neurodegenerative diseases. However, peripheral insulin that finds wide application in medical practice induces a hypoglycemic state which is destructive and dangerous to the brain, and only makes a slight contribution to the increase in central insulin level. This gives preference to the intranasal route of hormone administration. I-I improves learning and memory in healthy humans, it prevents cognitive deficit and other pathological changes in the brain of patients with Alzheimer's disease and in experimental animals with cognitive dysfunctions. ${ }^{20,21,25,26}$ However, there data are scarce on the influence of I-I on CNS functioning in diabetic individuals and experimental DM. ${ }^{27,28} \mathrm{I}-\mathrm{I}$ induced improvement in the behavioral, morphological and molecular abnormalities in the brain was only seen in T1DM mice. ${ }^{29}$ Our behavioral experiments demonstrated I-I induced improvement of long-term spatial memory and learning in rats with a neonatal model of T2DM. I-I decreases the search time to locate the hidden platform and swimming path length, and increases the swimming speed and the number of annulus crossings in insulin-treated diabetic rats compared with those untreated. These data suggest that I-I has a strong influence on CNS and prevents the cognitive decline in experimental T1DM and T2DM.

Improvement of cognitive functions by I-I is realized through the brain insulin signaling system and the integrated network, including signaling systems regulated by a large number of neurotransmitters and neuromediators controlling feeding behavior, learning and memory. ${ }^{10}$ Passing through intercellular clefts in the olfactory epithelium, I-I diffuses into the subarachnoidal space and is delivered to cerebrospinal fluid and brain tissue within 30 min. ${ }^{29,70-72}$ This leads to a rapid and significant increase in the content of insulin in the brain and induces the activation of insulin-regulated signaling cascades in neuronal and glial cells. Since the brain insulin concentration and the activity of insulin-regulated signaling pathways in the diabetic brain are, as a rule, reduced, I-I administration partially or completely restores these alterations and normalizes the functioning of the insulin signaling system. We found that I-I prevents the decrease in IRS2 expression in the hypothalamus of diabetic rats, which may contribute to the restoration of cognitive functions impaired in DM. In our view, normalization of IRS2 expression in the hypothalamus is likely to lead to a restoration of the insulin signaling system in this brain area, since IRS2 in the brain is of prime importance in the transduction of insulin signal to the intracellular effector proteins and mediates central insulin effects on the growth and energy homeostasis of the organism. . $^{30,31}$

Insulin is involved in the intercellular communication within brain structures, the hypothalamus and the limbic system in particular. Therefore, it is very important that restoration of IRS2-mediated signaling in the hypothalamus affects functioning of the other brain areas. ${ }^{10}$ It has previously been shown that the improvement in insulin signaling in the hypothalamus is capable of affecting signaling network in the hippocampus associated with impaired long-term potentiation in the diabetic brain. ${ }^{29,73,74}$ For example, peripheral insulin 
therapy of rats with STZ-induced T1DM protects against hippocampal potentiation deficit and prevents cognitive decline. ${ }^{75}$

To summarize, diabetic rats with a neonatal model of T2DM have cognitive deficit manifested as the impairment of their learning and spatial memory in an MWM test. It can be eliminated to a large extent by long-term I-I treatment. In the hypothalamus of diabetic rats, but not in the cortex and the olfactory bulbs, the expression of IRS2 is reduced. This may be one of the causes of cognitive deficit in DM. I-I restores the levels of IRS2. In our view, this contributes to the improvement in cognitive functions, as is the case of the MWM test. Our results give strong evidence for the benefit of I-I in the treatment of T2DM to prevent neurodegenerative diseases and cognitive deficit. They also indicate that the insulin signaling system, the major component of the overall hormonal network in the brain, is an important target in the therapy of DM-induced CNS diseases.

\section{References}

1. Kodl CT, Seaquist ER. Cognitive dysfunction and diabetes mellitus. Endocr Rev 2008;29:494-511.

2. Brands AM, Biessels GJ, de Haan EH, et al. The effects of type 1 diabetes on cognitive performance: a meta-analysis. Diabetes Care 2005;28:726-35.

3. Biessels GJ, Deary IJ, Ryan CM. Cognition and diabetes: a lifespan perspective. Lancet Neurol 2008;7:184-90.

4. Ruis C, Biessels GJ, Gorter KJ, et al. Cognition in the early stage of type 2 diabetes. Diabetes Care 2009;32:1261-5.

5. Gispen WH, Biessels GJ. Cognition and synaptic plasticity in diabetes mellitus. Trends Neurosci 2000;23:542-9.

6. Winocur G, Greenwood CE, Piroli GG, et al. Memory impairment in obese Zucker rats: an investigation of cognitive function in an animal model of insulin resistance and obesity. Behav Neurosci 2005;119:1389-95.

7. Moreira T, Malec E, Ostenson CG, et al. Diabetic type II Goto-Kakizaki rats show progressively decreasing exploratory activity and learning impairments in fixed and progressive ratios of a lever-press task. Behav Brain Res 2007;180:28-41.

8. Zhang T, Pan BS, Zhao B, et al. Exacerbation of poststroke dementia by type 2 diabetes is associated with synergistic increases of $\beta$-secretase activation and $\beta$ amyloid generation in rat brains. Neuroscience 2009;161:1045-56.

9. Schubert M, Gautam D, Surjo D, et al. Role for neuronal insulin resistance in neurodegenerative diseases. Proc Natl Acad
Sci USA 2004;101:3100-5.

10. Gerozissis K. Brain insulin, energy and glucose homeostasis; genes, environment and metabolic pathologies. Eur J Pharmacol 2008;585:38-49.

11. Shpakov A, Chistyakova 0., Derkach K., Bondareva V. Hormonal signaling systems of the brain in diabetes mellitus. In: Neurodegenerative Diseases, Book 1. RC Chang, ed. Rijeka, Croatia: Intech Open Access Publisher, 2011. In press.

12. Lee YH, White MF. Insulin receptor substrate proteins and diabetes. Arch Pharm Res 2004;27:361-70.

13. Clodfelder-Miller BJ, Zmijewska AA, Johnson GV, Jope RS. Tau is hyperphosphorylated at multiple sites in mouse brain in vivo after streptozotocin-induced insulin deficiency. Diabetes 2006;55:3320-5.

14. Schulingkamp RJ, Pagano TC, Hung D, Raffa RB. Insulin receptors and insulin action in the brain: review and clinical implications. Neurosci Biobehav Rev 2000; 24:855-72.

15. de la Monte SM, Wands JR. Alzheimer's disease is type 3 diabetes-evidence reviewed. J Diabetes Sci Technol 2008;2: 1101-13.

16. Ovalle F. Clinical approach to the patient with diabetes mellitus and very high insulin requirements. Diabetes Res Clin Pract 2010;90:231-42.

17. Mann DM, Woodward M, Ye F, et al. Trends in medication use among US adults with diabetes mellitus: glycemic control at the expense of controlling cardiovascular risk factors. Arch Intern Med 2009;169: 1718-20.

18. Cukierman-Yaffee T. The relationship between dysglycemia and cognitive dysfunction. Curr Opin Investig Drugs 2009; 10:70-4.

19. Henkin RI. Intranasal insulin: from nose to brain. Nutrition 2010;26:624-33.

20. Benedict C, Frey WH 2nd, Schiöth HB, et al. Intranasal insulin as a therapeutic option in the treatment of cognitive impairments. Exp Gerontol 2011;46:112-5.

21. Benedict C, Hallschmid M, Hatke A, et al. Intranasal insulin improves memory in humans. Psychoneuroendocrinology 2004; 29:1326-34.

22. Stockhorst U, de Fries D, Steingrueber HJ, Scherbaum WA. Insulin and the CNS: effects on food intake, memory, and endocrine parameters and the role of intranasal insulin administration in humans. Physiol Behav 2004;83:47-54.

23. Liu XF, Fawcett JR, Thorne RG, Frey WH 2nd. Non-invasive intranasal insulin-like growth factor-I reduces infarct volume and improves neurologic function in rats following middle cerebral artery occlusion. Neurosci Lett 2001;308:91-4.
24. Benedict C, Hallschmid M, Schultes B, et al. Intranasal insulin to improve memory function in humans. Neuroendocrinology 2007;86:136-42.

25. Reger MA, Watson GS, Frey WH 2nd, et al. Effects of intranasal insulin on cognition in memory-impaired older adults: modulation by APOE genotype. Neurobiol Aging 2006;27:451-8.

26. Hallschmid M, Benedict C, Schultes B, et al. Towards the therapeutic use of intranasal neuropeptide administration in metabolic and cognitive disorders. Regul Pept 2008;149:79-83.

27. Owens DR, Zinman B, Bolli G. Alternative routes of insulin delivery. Diabet Med 2003;20:886-98.

28. Khafagy el-S, Morishita M, Onuki Y, Takayama K. Current challenges in noninvasive insulin delivery systems: a comparative review. Adv Drug Deliv Rev 2007;59:1521-46.

29. Francis GJ, Martinez JA, Liu WQ, et al. Intranasal insulin prevents cognitive decline, cerebral atrophy and white matter changes in murine type I diabetic encephalopathy. Brain 2008;131:3311-34.

30. Burks D, de Mora J, Schubert M, et al. IRS2 pathways integrate female reproduction and energy homeostasis. Nature 2000;407: 377-82.

31. Kubota N, Terauchi Y, Tobe K, et al. Insulin receptor substrate 2 plays a crucial role in beta cells and the hypothalamus. J Clin Invest 2004;114:917-27.

32. Guidelines for the treatment of animals in behavior research and teaching. Animal Behaviour 2006;71:245-53.

33. Hemmings SJ, Spafford D. Neonatal STZ model of type II diabetes mellitus in the Fischer 344 rat: characteristics and assessment of the status of the hepatic adrenergic receptors. Int $\mathrm{J}$ Biochem Cell Biol 2000;32:905-19.

34. Blondel 0, Bailbé D, Portha B. Relation of insulin deficiency to impaired insulin action in NIDDM adult rats given streptozocin as neonates. Diabetes 1989;38:6107.

35. Thorne RG, Frey WH 2nd. Delivery of neurotrophic factors to the central nervous system: pharmacokinetic considerations. Clin Pharmacokinet 2001;40:907-46.

36. Morris R. Developments of a water-maze procedure for studying spatial learning in the rat. J Neurosci Methods 1984;11:47-60.

37. Gleason TC, Dreiling JL, Crawley JN. Rat strain differences in response to galanin on the Morris water task. Neuropeptides 1999;33:265-70.

38. Van Dam D, Lenders G, De Deyn PP. Effect of Morris water maze diameter on visualspatial learning in different mouse strains. Neurobiol Learn Mem 2006;85: 
164-72.

39. Schenk F. The Morris water maze (is not a maze). In: A handbook of spatial research paradigms and methodologies. Vol. 2. Clinical and Comparative Studies. N Foreman, R Gillett (eds.) East Sussex, Psychology Press, 1998, pp 145-88.

40. McNamara RK, Skelton RW. The neuropharmacological and neurochemical basis of place learning in the Morris water maze. Brain Res Brain Res Rev 1993;18: $33-49$.

41. Havrankova J, Roth J, Brownstein M. Insulin receptors are widely distributed in the central nervous system of the rat. Nature 1978;272:827-9.

42. Neville DM Jr. Isolation of an organ specific protein antigen from cell-surface membrane of rat liver. Biochim Biophys Acta 1968;154:540-52.

43. Rusakov YuI, Moriyama S, Bondareva VM, et al. Isolation and characterization of insulin in Russian sturgeon (Acipenser guldenstaedti). J Pept Res 1998;51:395400.

44. Shpakov A0, Kuznetsova LA, Plesneva SA, et al. Functional defects in adenylyl cyclase signaling mechanisms of insulin and relaxin action in skeletal muscles of rat with streptozotocin type 1 diabetes. Cent Eur J Biol 2006;1:530-44.

45. Reaven GM, Thompson LW, Nahum D, Haskins E Relationship between hyperglycemia and cognitive function in older NIDDM patients. Diabetes Care 1990;13: 16-21.

46. Strachan MW, Deary IJ, Ewing FM, Frier BM. Is type II diabetes associated with an increased risk of cognitive dysfunction? A critical review of published studies. Diabetes Care 1997;20:438-45.

47. Ryan CM, Geckle M. Why is learning and memory dysfunction in Type 2 diabetes limited to older adults? Diabetes Metab Res Rev 2000;16:308-15.

48. Sterwart R, Liolitsa D. Type 2 diabetes mellitus, cognitive impairment and dementia. Diabet Med 1999;16:93-112.

49. Awad N, Gagnon M, Messier C. The relationship between impaired glucose tolerance, type 2 diabetes, and cognitive function. J Clin Exp Neuropsychol 2004;26: 1044-80.

50. van Harten B, Oosterman JM, Potter van Loon BJ, et al. Brain lesions on MRI in elderly patients with type 2 diabetes mellitus.
Eur Neurol 2007:57:70-4.

51. Bélanger A, Lavoie N, Trudeau F, et al. Preserved LTP and water maze learning in hyperglycaemic-hyperinsulinemic ZDF rats. Physiol Behav 2004;83:483-94.

52. Greenwood CE, Winocur G. High-fat diets, insulin resistance and declining cognitive function. Neurobiol Aging 2005;26:42-5.

53. Sakata A, Mogi M, Iwanami J, et al. Female exhibited severe cognitive impairment in type 2 diabetes mellitus mice. Life Sci 2010;86:638-45.

54. Srinivasan K, Ramarao P. Animal models in type 2 diabetes research: an overview. Indian J Med Res 2007;125:451-72.

55. Portha B, Picon L, Rosselin G. Chemical diabetes in the adult rat as the spontaneous evolution of neonatal diabetes. Diabetologia 1979;17:371-7.

56. Shpakov A0, Bondareva VM, Chistiakova OV. Functional state of adenylyl cyclase signaling system in reproductive tissues of rats with experimental type 1 diabetes. Tsitologiia 2010;52:177-83.

57. Shpakov AO, Derkach KV, Bondareva VM. A decrease in the sensitivity of adenylyl cyclase and heterotrimeric $g$ proteins to chorionic gonadotrophin and peptide hormones action in the tissues of reproductive system of rats with experimental type 2 diabetes. Biomed Khim 2010;56:700-9.

58. Brüning JC, Gautam D, Burks DJ, et al. Role of brain insulin receptor in control of body weight and reproduction. Science 2000;289:2122-5.

59. Li ZG, Zhang W, Sima AA. Alzheimer-like changes in rat models of spontaneous diabetes. Diabetes 2007;56:1817-24.

60. Fioramonti X, Contié S, Song Z, et al. Characterization of glucosensing neuron subpopulations in the arcuate nucleus: integration in neuropeptide $\mathrm{Y}$ and pro-opio melanocortin networks? Diabetes 2007;56: 1219-27.

61. Gelling RW, Morton GJ, Morrison CD, et al. Insulin action in the brain contributes to glucose lowering during insulin treatment of diabetes, Cell Metab 2006;3:67-73.

62. Lin X, Taguchi A, Park S, et al. Dysregulation of insulin receptor substrate 2 in beta cells and brain causes obesity and diabetes. J Clin Invest 2004;114:908-16.

63. Withers D, Gutierrez J, Towery $H$. Disruption of IRS-2 causes type 2 diabetes in mice. Nature 1998;391:900-4.

64. Burks DJ, Font de Mora J, Schubert M, et al. IRS-2 pathways integrate female reproduction and energy homeostasis. Nature 2000;407:377-82.

65. Niswender KD, Morrison CD, Clegg DJ, et al. Insulin activation of phosphatidylinositol 3-kinase in the hypothalamic arcuate nucleus: a key mediator of insulin-induced anorexia. Diabetes 2003;52:227-31.

66. Baskin DG, Sipols AJ, Schwartz MW, White MF. Immunocytochemical detection of insulin receptor substrate-1 (IRS-1) in rat brain: colocalization with phosphotyrosine. Regul Pept 1993;48:257-66.

67. Araki E, Lipes MA, Patti ME, et al. Alternative pathway of insulin signalling in mice with targeted disruption of the IRS-1 gene. Nature 1994;372186-90.

68. Jackson J, Paulose CS. Enhancement of [m-methoxy 3H]MDL100907 binding to 5 HT2A receptors in cerebral cortex and brain stem of streptozotocin induced diabetic rats. Mol Cell Biochem 1999;199:815.

69. Shankar PN, Joseph A, Paulose, CS. Decreased [3H] YM-09151-2 binding to dopamine D2 receptors in the hypothalamus, brainstem and pancreatic islets of streptozotocin-induced diabetic rats. Eur J Pharmacol 2007;557:99-105.

70. Born J, Lange T, Kern W, et al. Sniffing neuropeptides: a transnasal approach to the human brain. Nat Neurosci 2002;5: 514-6.

71. Francis G, Martinez J, Liu W, et al. Intranasal insulin ameliorates experimental diabetic neuropathy. Diabetes 2009;58: 934-45.

72. Dhuria SV, Hanson LR, Frey WH. Intranasal delivery to the central nervous system: mechanisms and experimental considerations. J Pharm Sci 2010;99:1654-73.

73. Biessels GJ, Kamal A, Ramakers GM, et al. Place learning and hippocampal synaptic plasticity in streptozotocin-induced diabetic rats. Diabetes 1996;45:1259-66.

74. Kamal A, Biessels GJ, Gispen WH, Ramakers GM. Synaptic transmission changes in the pyramidal cells of the hippocampus in streptozotocin-induced diabetes mellitus in rats. Brain Res 2006; 1073-4:276-80.

75. Biessels GJ, Kamal A, Urban IJ, et al. Water maze learning and hippocampal synaptic plasticity in streptozotocin-diabetic rats: effects of insulin treatment. Brain Res 1998;800:125-35. 